\title{
A Protocol for In-vitro Direct Plant Regeneration from Leaf Tissues for Micropropagation of Sugarcane
}

\author{
D.N. Balagalla*, A. Wijesuriya, N. P. Ranathunge ${ }^{1}$ and A.M.M.S. Perera \\ Sugarcane Research Institute \\ Uda Walawe \\ Sri Lanka
}

\begin{abstract}
An efficient protocol to produce higher number of shoots was developed for Sugarcane (Saccharum Hybrid spp.) variety SL 96 328. In-vitro direct shoot regeneration from sugarcane leaf spindle tissues was achieved in modified Murashige and Skoog medium supplemented with $1.5 \mathrm{mg} / \mathrm{L}$ of Benzylaminopurine, $0.5 \mathrm{mg} / \mathrm{L}$ of Kinetin, $0.5 \mathrm{mg} / \mathrm{L}$ of 2,4-D, 1 $\mathrm{mg} / \mathrm{L}$ of Indole-3-acetic acid and $400 \mathrm{mg} / \mathrm{L}$ of Cysteine Hydrochloride. The survival rate of explants and number, length and vigour of shoots generated from explants, and minimal number of chlorophyll-mutated shoots per explant were recorded. Explants incubated in the dark for two weeks enhanced direct shoot regeneration and produced the highest number of shoots (25) from a single explant. The best diameter and the thickness of the explant were 3 $\mathrm{mm}$ and $2 \mathrm{~mm}$, respectively. The amplification of Simple Sequence Repeat primer using Polymerase Chain Reaction (PCR) revealed that the plants obtained through in-vitro directly-regenerated shoots were genetically more identical than those generated from stem cuttings. Nested PCR confirmed that the plantlets obtained from direct shoot regeneration were free from sugarcane white leaf disease (WLD) phytoplasma. Thus, the in-vitro protocol suggested for rapid micropropagation of sugarcane through this study can be adopted in producing genetically-homogenous and WLD-free planting material in establishing sugarcane nurseries.
\end{abstract}

Keywords: Direct shoot regeneration, in-vitro culture, rapid multiplication, sugarcane

\section{INTRODUCTION}

Commercially-grown sugarcanes (Saccharum Hybrid spp.) are perennial grasses belonging to family Poaceae that thrive well in tropical and frost-free warm temperate areas in the world. Non-availability of quality planting material in required quantities is identified as a main constraint for sugarcane production in Sri Lanka. A gradual decline in average sugarcane yield in commercial sugarcane plantations is observed since mid-1980s although new high-yielding varieties have been introduced. One of the main reasons for this yield decline was identified as "varietal degeneration" due to accumulation of systemic diseases in the crop over the years due to vegetative propagation.

In Sri Lanka, smut (Sporisoriums citamineum), leaf scald (Xanthomonoas albilineans) and white leaf (Phytoplasma) are the major sugarcane diseases, of which white leaf disease (WLD) has been identified as the major constraint for sugarcane production at present. Smut

1 Department of Agricultural Biology, Faculty of Agriculture, University of Ruhuna, Sri Lanka.

* Corresponding author: dineeshanipuni@gmail.com 
and leaf scald disease can be managed in commercial plantations using resistant varieties. The absence of varieties with WLD-resistance and desirable agronomic features coupled with lack of proven techniques to successfully eliminate the causative agent of WLD from the infected cane, have resulted in the rapid spread of this disease in commercial plantations. In Sri Lanka, reduction of cane yield and sugar recovery due to WLD has been estimated to be $82 \%$ and $44 \%$, respectively.

Meristem culture is the only technique proven for elimination of systemic sugarcane diseases including those caused by viruses (Perera, 2012). The Sugarcane Research Institute (SRI) of Sri Lanka has developed a protocol for sugarcane meristem culture, which is used to produce genetically-pure and disease-free plants (Atapattu et al., 2010).

Direct regeneration of shoots from in-vitro cultured young leaf segments of sugarcane has been the interest among scientists to produce disease-free and genetically-identical plants (Geijskes et al., 2003). It is assumed that the technique has the capacity to generate 15 multiple shoots from one leaf spindle explant and that there is a possibility of having $15 \mathrm{such}$ explants from one leaf spindle segment. A cane top possesses one apical meristem and one leaf spindle segment. Therefore, it is clear that direct regeneration of shoots from leaf spindle explants has the potential of generating 225 multiple shoots from one leaf spindle segment in contrast to one multiple shoot from meristem culture. The other culturing steps i.e. in-vitro rapid multiplication of shoots through passage culture and rooting of multiple shoots, are common to these techniques, too. Manipulation of the concentrations of phyto-hormones, e.g. auxin and cytokine, in culture media and the culture conditions has been investigated in optimizing the protocols for any in-vitro culture system including direct plant regeneration technique (Lakshmanan et al., 2006; Khan et al., 2009; Singh et al., 2007).

This research was undertaken with the objectives of developing a tissue explanting technique, optimizing plant growth regulators, improving culture medium and perfecting culture conditions in in-vitro direct shoot regeneration from sugarcane leaf spindle tissues. This process is considered as the first step to employ with in-vitro rapid multiplication of shoots through passage culture and rooting of multiple shoots as in sugarcane meristem culture. Confirmation of genetic similarity of the plants produced and production of WLDfree plants by the technique were also investigated.

\section{MATERIALS AND METHODS}

\section{Preparation of culture media}

One hundred and seventy-five different combinations of phyto-hormones, namely Benzyl aminopurine (BA), Kinetin, 2, 4-Dichlorophenoxyacetic acid (2, 4-D) and Indole-3aceticacid (IAA) were tested for in-vitro direct shoot regeneration from leaf spindle explants of sugarcane using the standard MS medium (Murashigeand Skoog, 1962). Sucrose at the concentration of $30 \mathrm{~g} / \mathrm{L}$, Polyvinylpyrrolidone (PVP) $600 \mathrm{mg} / \mathrm{L}$ and Cysteine Hydrochloride $400 \mathrm{mg} / \mathrm{L}$ were added to the medium. Phytagel at a concentration of $2 \mathrm{~g} / \mathrm{L}$ was used as the gelling agent. The $\mathrm{pH}$ of the medium was adjusted to 5.8. Media were heated up to the boiling point, poured into culture bottles and autoclaved after capping the mouths of the bottles with aluminium foils. Thirty millilitres of medium in each culture bottle was used for culturing three explants in different treatment combinations. 


\section{Explant preparation and culture}

Young cane tops of the sugarcane (Saccharum Hybrid spp.) variety SL 96328 were obtained from a mericloned-nursery established under polytunnel condition. The mature leaf whorls of these cane tops were removed until the leaf spindles were exposed. The leaf spindles were first washed under running tap water for $5 \mathrm{~min}$. Five to six $\mathrm{cm}$-long leaf spindle pieces were surface sterilized by dipping them in $70 \%$ ethanol solution for $30 \mathrm{sec}$. The explants at the size of $3 \mathrm{~mm}$ (diameter) $\times 2 \mathrm{~mm}$ (thicknesses) were placed on the culture medium (Figure 1) under laminar air flow condition, in the dark for incubation.

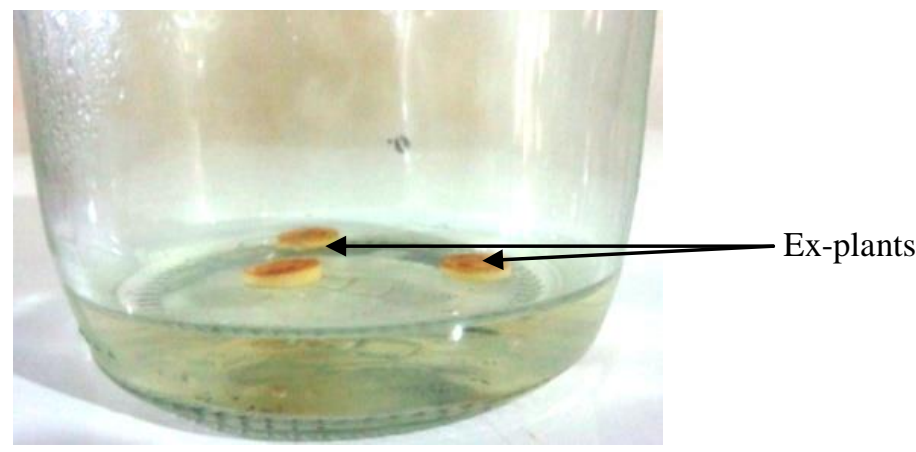

Figure 1. Explants with $2 \mathrm{~mm}$ thickness in culture

After two weeks of dark incubation, explants were exposed to artificial light with an intensity of 2000-3000 lux for 10 weeks. These explants were transferred into fresh medium after 4 weeks in view of reducing browning effect.

\section{Screening of the best hormone combinations and protocol perfection}

Based on survival of the explants, non-formation of calli and development of directly regenerated shoots from explants, four hormonal combinations (Table 1) were selected for further studies. Perfection of the steps involved in this in-vitro culture protocol was done using these four hormonal combinations. Donor plants at the age groups of 3-4, 5-6, 7-8, 910 and 11-12 months were used to identify the best age of the donor plant for explanting tissues. Leaf spindle explants of the diameters of 1,2, 3, and $4 \mathrm{~mm}$ and thicknesses of 1,2 and $3 \mathrm{~mm}$ were used to identify the optimum diameter and thickness of the explants.

\section{Experimental design and data analysis}

The cultures were kept on the racks in the culture room in a complete randomized layout with 30 replicates per treatment. Data on survival of the explants under culture, number of shoots generated per explant, shoot length and shoot vigour and number of shoots with chlorophyll mutations per explant were recorded at weekly intervals. The survival of explants in the treatment combinations was recorded as a binary system where 0 and 1 were allocated to dead and living cultures, respectively. Vigour of the shoots was recorded using a 1-5 Likert scale based on shoot growth as described below (Table 1).

The data on the variables; survival of the explant and number of shoots developed from an explant were recorded for each set of cultures at weekly intervals from the first week to six weeks in the dark to identify the optimum period for dark incubation of explants. 
Table 1. Likert scale used to measure the vigour of the shoots

\begin{tabular}{cl}
\hline Rank & \multicolumn{1}{c}{ Description } \\
\hline 1 & Explant is alive but no shoot formation \\
2 & Slow shoot growth \\
3 & Moderate shoot growth \\
4 & High shoot growth \\
5 & Excellent shoot growth \\
\hline
\end{tabular}

The Arc Sin transformation (Gomez and Gomez, 1984) was used to analyse percentage culture survival. Number of shoots developed per explant and shoot length were analysed using ANOVA and subsequent mean separation. Kruskal-Wallis test, which approximates a chi-square distribution, was employed in the analysis of shoot vigour. The Kruskal-Wallis inequality was used to calculate the critical difference as suggested by Siegel and Castellan (1988) to compare the means scores of shoot vigour for different treatments. The procedure NPAR1WAY in SAS 9.0 was employed in the analysis.

\section{Confirmation of genetic similarity and plants free from WLD-phytoplasma}

Genetic similarity was investigated using two plant populations of the sugarcane variety SL 96328 , each with 25 plants developed through in-vitro direct shoot regeneration protocol and through stem cuttings. The DNA was extracted using CTAB method and PCR was performed subsequently using 10 SSR primers specific to sugarcane representing 8 polymorphic and 2 monomorphic primers. The amplification conditions were; denaturation at $94^{\circ} \mathrm{C}$, annealing temperature (Table 5) and extension at $72^{\circ} \mathrm{C}$. Agarose gel electrophoresis was done and the resulting amplicons were recorded as presence of band ' 1 ' and absence of bands ' 0 'from SSR amplification profile. Similarity matrices were developed for SSR amplification profile using the Jaccard method (Sesli and Yegenoglu, 2010). These similarity matrices were used to generate the dendrograms by the Group Average method available in Genstat 17.

Two universal primers for phytoplasma were used to detect WLD phytoplasma in 25 plants that were directly regenerated from the leaf spindle explants through nested PCR. Primer sequence and their annealing temperatures are given Table 2.

Table 2. Sequence of primers and their annealing temperatures (AT)

\begin{tabular}{lccr}
\hline Primer & \multicolumn{1}{c}{ Reverse } & Forward & AT \\
\hline P1/P7 & AAGAATtTGATCCTGGCTCAGGATt & CGTCCTTCATCGGCTCTT & $55^{\circ} \mathrm{C}$ \\
P399/P1694 & GAAACGACTGCTAAGACTGG & TGACGGGCGGTCTGTACAAACCCCG & $60^{\circ} \mathrm{C}$ \\
\hline
\end{tabular}

\section{RESULTS AND DISCUSSION}

The four promising hormone combinations selected out of 175 combinations tested initially for in-vitro direct shoot regeneration from leaf spindle explants of sugarcane were listed in Table 3. 


\section{Survival of explants and regeneration of shoots during dark incubation}

No significant differences $(p>0.05)$ were observed between treatments for the percentage of survival of explants during the period of dark incubation. The highest percentage survival rates of explants were observed after 1 week of incubation in dark, which ranged from 87.4 (Treatment 4) to 93.5 (Treatment 3). A decline in the percentage survival of explants was observed thereafter (Figure 2).

Table 3. The four hormone combinations selected for perfection of in-vitro direct shoot regeneration protocol from sugarcane leaf spindle explants

\begin{tabular}{cccccc}
\hline Treatment & $\begin{array}{c}\mathrm{BA} \\
\mathrm{mg} / \mathrm{L}\end{array}$ & $\begin{array}{c}\text { Kinetin } \\
\mathrm{mg} / \mathrm{L}\end{array}$ & $\begin{array}{c}2,4-\mathrm{D} \\
\mathrm{mg} / \mathrm{L}\end{array}$ & $\begin{array}{c}\text { IAA } \\
\mathrm{mg} / \mathrm{L}\end{array}$ & $\begin{array}{c}\text { Cysteine hydrochloride } \\
\mathrm{mg} / \mathrm{L}\end{array}$ \\
\hline 1 & 1.5 & 0.1 & 0.5 & 1 & 400 \\
2 & 2.0 & 0.1 & 0.5 & 1 & 400 \\
3 & 1.5 & 0.5 & 0.5 & 1 & 400 \\
4 & 2.0 & 0.5 & 0.5 & 1 & 400 \\
\hline
\end{tabular}

Treatment 3 gave the highest number of shoots per explant, which was significantly different $(p<0.05)$ from the other treatments from two to five weeks of dark incubation. The highest number of shoots was produced after two weeks of dark incubation of explants in all four treatments and the mean number of shoots produced in Treatment 3 (25) was significantly different $(p<0.05)$ from the rest.

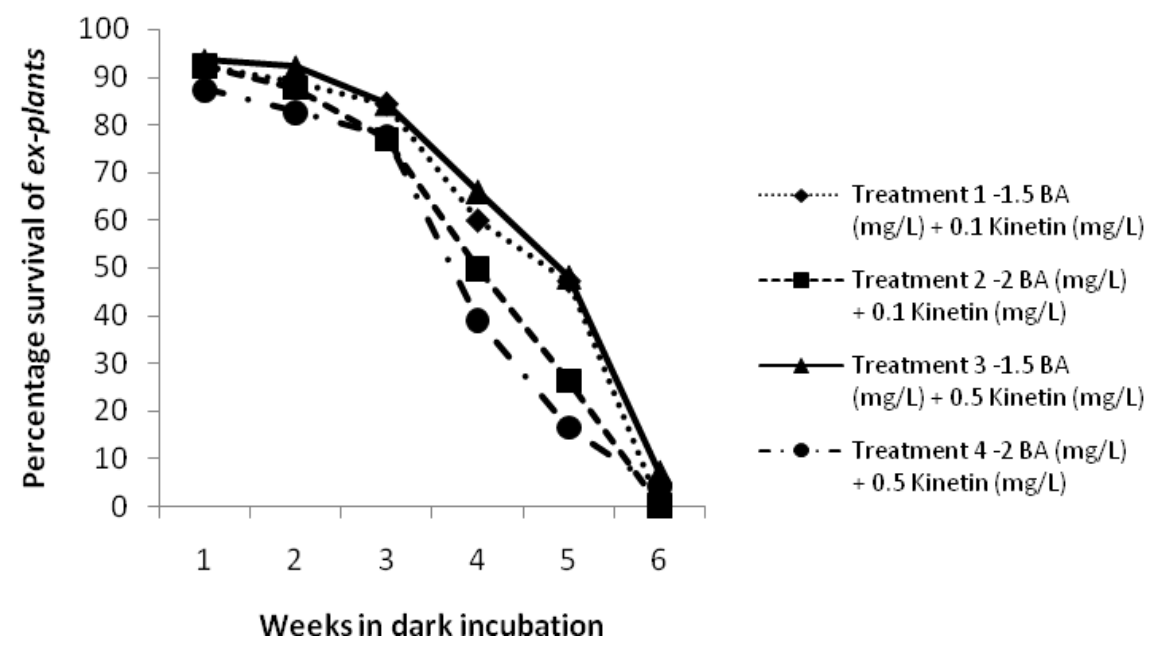

Figure 2. Percentage survival of explants during incubation in dark

\section{Number of in-vitro generated shoots, shoot length and shoot vigour}

After 8 and 12 weeks of culture, the highest number of shoots per explant was reported in Treatment 3 (Figure 3) which was significantly different $(p<0.05)$ from the rest. The results were similar to that in sugarcane variety NIA 98 observed by Khan et al. (2009) who reported of shoot initiation within four weeks of culture.

After 8 weeks of culture, the highest average shoot length was recorded in Treatment 3 followed by Treatment $1(p>0.05)$ Treatments 2 and 4 recorded a significantly lower shoot 
length compared to treatments 1 and $3(p<0.05)$. After 12 weeks, the maximum shoot length was observed in Treatment 1 , followed by Treatment $3(p>0.05)$. The results obtained after 12 weeks were similar to those observed at 8 weeks of culture, where the differences of average shoot lengths reported for treatments 2 and 4 were significantly lower $(p<0.05)$ compared to treatments 1 and 3 .

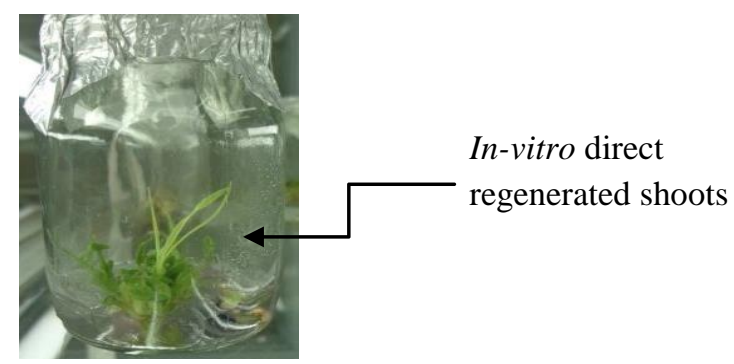

Figure 3. In-vitro direct regenerated shootsfrom Treatment 3 (BA $1.5 \mathrm{mg} / \mathrm{L}$ and kinetin $0.5 \mathrm{mg} / \mathrm{L}$ in the presence of 2,4-D $0.5 \mathrm{mg} / \mathrm{L}$, IAA $1 \mathrm{mg} / \mathrm{L}$ and Cysteine Hydrochloride $400 \mathrm{mg} / \mathrm{L}$

In the $8^{\text {th }}$ week, the shoots generated from the Treatment 3 showed a significantly higher shoot vigour compared to the other treatments $(p<0.05)$. In the $12^{\text {th }}$ week, no significant differences were observed between mean scores of treatments 3 and $4(p>0.05)$. Considering the number of in-vitro generated shoots, their length and vigour, the hormone combination in Treatment 3 was identified as the best for in-vitro direct shoot regeneration from leaf spindle tissues of sugarcane.

\section{Age of the donor for explanting tissues}

None of the hormone combinations produced shoots from the explants taken at the age of three to four months of the donor plant. At five to six months age of the mother plant, the highest number of shoots per explant (21) was reported in Treatment $3(p<0.05)$. A similar response was observed in explants taken at the age of seven to eight months of the donor. The explants of the donors of age groups nine to ten months and 11 to 12 months did not produce any shoots in all four treatments. Therefore, the best age of the donor plant for $e x$ planting tissues was identified as five to six months for in-vitro direct shoot regeneration from leaf tissues of sugarcane.

\section{Size of explant}

In the first four weeks of culture, explants of $1 \mathrm{~mm}$ diameter did not produce any shoot. A significantly high mean number of shoots $(17 ; p<0.05)$ was generated from the $3 \mathrm{~mm}$ explants while other diameters of explants tested gave relatively a lower number of shoots. Desai et al. (2004) reported that explants of 3-6 mm in diameter showed swelling of the explants and initiation of small embryo-like structures in the first week of culture. Khan et al. (2009) explained that the immature leaf segments of 2-4 $\mathrm{mm}$ in diameter showed swelling of the explants in the first week of culture. These results and the results of our experiments imply that the best diameter of the explant to produce shoots is $3 \mathrm{~mm}$.

The hormone combination in Treatment 3 gave a better explant survival rate. Moreover, the highest number of regenerated shoots from explants at thicknesses 1, 2, and $3 \mathrm{~mm}$. Explants having $2 \mathrm{~mm}$ thickness gave the highest number of shoots $(p<0.05)$ among the rest. Therefore, the results of the present study showed that the explants with $2 \mathrm{~mm}$ thickness 
under the hormone combination in Treatment 3 gave the highest shoots per explant. This result is in conformity of the findings of Khan et al. (2009), who reported that leaf spindle explants at a thickness of 2-4 $\mathrm{mm}$ had the best response for shoot organogenesis. The results revealed that the leaf spindle explants of $3 \mathrm{~mm}$ in diameter and $2 \mathrm{~mm}$ in thickness was the best size for in-vitro shoot regeneration in sugarcane.

\section{Chlorophyll-mutated shoots produced from explants}

After 8 and 12 weeks of culture, the lowest number of chlorophyll mutated shoots per explant $(\mathrm{p}<0.05)$ was reported in Treatment 3 (BA $1.5 \mathrm{mg} / \mathrm{L}$ and Kinetin $0.5 \mathrm{mg} / \mathrm{L})($ Table 4). Regeneration of albino plantlets suggested the appearance of chlorophyll mutants and low number of chlorophyll mutants resemble low genetic variability in the obtained shoots (Khan et al., 2009).

Table 4. Number of chlorophyll-mutated shoots per explant under different hormone combinations

\begin{tabular}{ccc}
\hline $\begin{array}{c}\text { Hormone } \\
\text { combination }\end{array}$ & $\begin{array}{c}\text { Mean number of chlorophyll- mutants per explant } \\
\text { After } 8 \text { weeks }\end{array}$ & After 12 weeks \\
\hline 1 & $6.80^{\mathrm{b}}$ & $7.00^{\mathrm{b}}$ \\
2 & $9.40^{\mathrm{a}}$ & $9.43^{\mathrm{a}}$ \\
3 & $0.63^{\mathrm{c}}$ & $1.00^{\mathrm{c}}$ \\
4 & $9.66^{\mathrm{a}}$ & $9.53^{\mathrm{a}}$ \\
\hline
\end{tabular}

Means with same letters are not significantly different at the $\alpha$-level 0.05

\section{Confirmation of genetic similarity and free from WLD-phytoplasma}

The dendrograms generated using the of Group Average method (Genstat 17) for 25 plants produced through in-vitro direct shoot regeneration protocol and 25 plants obtained from seed sets are depicted in Figure $4 \mathrm{a}$ and $4 \mathrm{~b}$, respectively. Table 5 shows the summarized information of the primers used in the SSR study together with their annealing temperatures and number of loci. The size of the amplicons is listed against the primers.

4a)

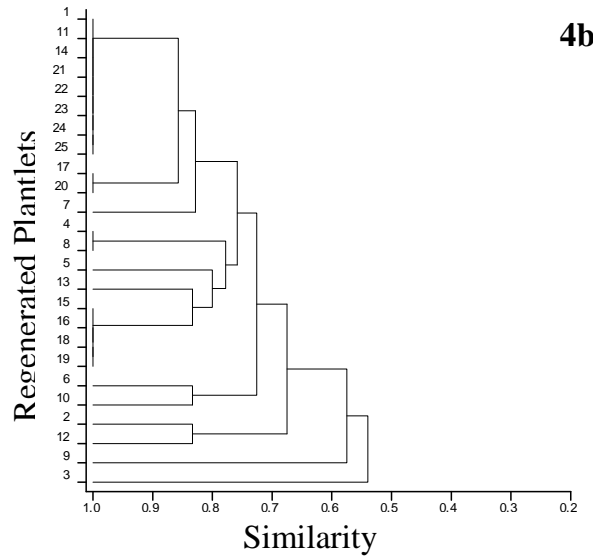

4b)

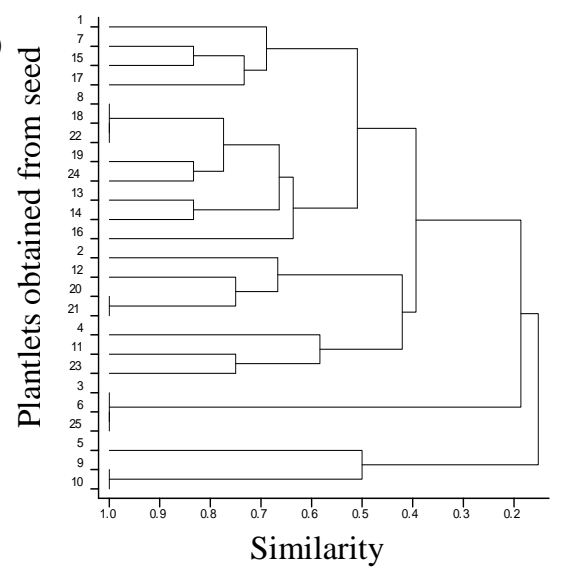

Figure 4. Dendrogram obtained from similarity matrices based on Jaccard method for twenty-five plantlets obtained separately through; 4a: In-vitro direct shoot regeneration and $4 \mathrm{~b}$ : Seed setts 
Figure 5 illustrates the amplification profile of plantlets tested for WLD phytoplasma along with the positive and negative controls. All the plants tested for WLD did not show amplicons at the $1280 \mathrm{bp}$ region. However, the DNA isolated from disease-infected plants showed amplicons at 1280 bp in $2.0 \%$ Agarose gel where $1 \mathrm{~kb}$ ladder was used. Sample numbers 7, 10, 13 and 15 showed an unspecific band amplification, while number 18 was the positive showing a band at 1280 bp (Perera et. al., 2012). These results confirmed that the plantlets produced through the protocol developed by this study through in-vitro direct shoot regeneration from leaf spindle tissues of sugarcane is capable of producing sugarcane WLDfree planting materials.

Table 5. Number of loci/bands, number of polymorphic bands and the range of the size of bands observed for different primers used in the study

\begin{tabular}{ccccc}
\hline $\begin{array}{c}\text { Name of } \\
\text { the primer }\end{array}$ & $\begin{array}{c}\text { Annealing } \\
\text { temperature } \\
\left({ }^{\mathbf{C}} \mathbf{C}\right)\end{array}$ & $\begin{array}{c}\text { No. of } \\
\text { loci/ } \\
\text { bands }\end{array}$ & $\begin{array}{c}\text { No. of } \\
\text { polymorphic } \\
\text { bands }\end{array}$ & $\begin{array}{c}\text { Range of the size of } \\
\text { band(bp) }\end{array}$ \\
\hline P-14 & 58 & 1 & 1 & $500-750$ \\
P-19 & 56 & 1 & 1 & $250-500$ \\
P-38 & 59 & 2 & 2 & $250-500$ \\
P-48 & 56 & - & - & - \\
P-49 & 53 & - & - & - \\
P-66 & 58 & 1 & 1 & $250-500$ \\
P-73 & 58 & 3 & 3 & $100-500$ \\
P-90 & 55 & 1 & 1 & $100-250$ \\
P-142 & 60 & 2 & 2 & $100-500$ \\
P-151 & 54 & - & - & - \\
\hline
\end{tabular}

(-)indicates no bands

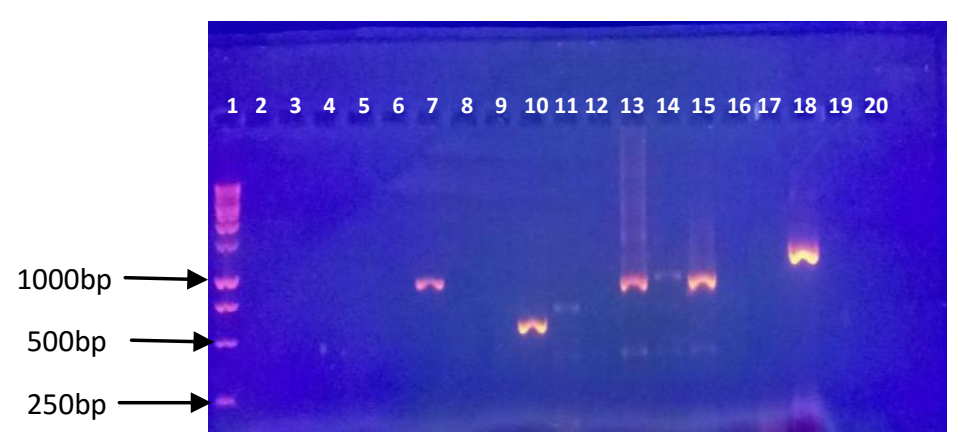

Figure 5. Agarose gel picture on nested PCR products

This technique can be further developed to produce sugarcane planting materials at largescale in the establishment and maintenance of commercial sugarcane nurseries, with increased homogeneity of planting materials that are free from WLD phytoplasma. Suggested protocol for in-vitro direct plant generation for sugarcane is given in Table 6 . 
Table 6. Suggested protocol for in-vitro direct plant generation for sugarcane

\begin{tabular}{|c|c|c|}
\hline & Process & Description \\
\hline 1. & Explant preparation & $\begin{array}{l}\text { Best age of the mother plant is five to six } \\
\text { months (mother plants should be originated } \\
\text { through mericloning) } \\
\text { Explant used should be } 3 \mathrm{~mm} \text { in diameter and } \\
2 \mathrm{~mm} \text { in thickness }\end{array}$ \\
\hline 2. & $\begin{array}{l}\text { Preparation of culture } \\
\text { medium supplemented with } \\
\text { phyto-hormone combinations }\end{array}$ & $\begin{array}{l}\text { BA } 1.5 \mathrm{mg} / \mathrm{L}, \text { Kinetin } 0.5 \mathrm{mg} / \mathrm{L}, 2,4-\mathrm{D} 0.5 \\
\mathrm{mg} / \mathrm{L} \text {, IAA } \mathrm{mg} / \mathrm{L} \text { and Cysteine Hydrocholride } \\
400 \mathrm{mg} / \mathrm{L}\end{array}$ \\
\hline 3. & Dark Incubation & Two weeks of initial dark incubation \\
\hline 4. & Light incubation & $\begin{array}{l}\text { Explants after dark incubation should be } \\
\text { transferred to light with } 10 \text { weeks of light } \\
\text { incubation to generate the highest number of } \\
\text { shoots }\end{array}$ \\
\hline 5. & Rooting & Two weeks in rooting media \\
\hline 6. & Hardening process & $\begin{array}{l}\text { Transfer to polytunnel at the age of } 14 \text { weeks } \\
\text { of incubation }\end{array}$ \\
\hline
\end{tabular}

\section{CONCLUSIONS}

The phyto-hormone combination with $1.5 \mathrm{mg} / \mathrm{L}$ of BA, $0.5 \mathrm{mg} / \mathrm{L}$ of Kinetin and $0.5 \mathrm{mg} / \mathrm{L}$ of 2,4-D, $1 \mathrm{mg} / \mathrm{L}$ of IAA and $400 \mathrm{mg} / \mathrm{L}$ of Cysteine Hydrochloride was identified as the best hormone combination to use with modified MS medium for direct in-vitro shoot regeneration from leaf spindle tissues of sugarcane, as the first step of producing a large number of shoots compared to meristem culture. As the subsequent steps i.e. passage culture for in-vitro rapid multiplication of shoots and rooting of multiple shoots, are similar to that of meristem culture, the protocols used at these two steps in meristem culture are also applicable to the new protocol involved with initial in-vitro shoot regeneration from leaf spindle explants. The best age of the donor plants for ex-planting tissues is 5-6 months. The explants of $3 \mathrm{~mm}$ in diameter and $2 \mathrm{~mm}$ in thickness are the ideal for in-vitro shoot regeneration. Two weeks incubation period in dark of cultured-explants prior to their transfer to light is required for developing the maximum number of in-vitro regenerated shoots.

\section{ACKNOWLEDGEMENT}

The authors are thankful to Dr. A. P. Keerthipala, Director/Chief Executive Officer of the Sugarcane Research Institute (SRI) at Uda Walawe, Sri Lanka for granting permission to carry out this research project at the SRI and for correction of the manuscript. The contribution of Dr. (Mrs.) Wasana Wijesuriya, Principal Research Officer (Biometry), Rubber Research Institute of Sri Lanka, Agalawatte, Sri Lanka in statistical analysis of data is highly acknowledged. 


\section{REFERENCES}

Atapattu, G.D.T., Perera, A.M.M.S., Ariyawansha, B.D.S.K., Manel, D. and Wijesuriya, A., (2010). Optimization of Sugarcane (Saccharum Hybrid spp.) meristem culture protocol with respect to phyto-hormone levels. Proceedings of the third Symposium on Plantation Crop Research. September 30 and October 01, Colombo, Sri Lanka. pp. 147-156.

Desai, N.S., Suprasanna, P. and Bapat, V.A. (2004). Simple and reproducible protocol for direct somatic embryogenesis from cultured immature inflorescence segments of sugarcane (Saccharum spp.). Curr. Sci. 87,764-768.

Geijskes, R.J., Wang, L., Lakshmanan, P., McKeon, M.G., Berding, N.,Swain, R.S., Elliott, A.R., Grof, C.P.L., Jackson, J.A. and Smith, G. R. (2003). Proc. of Aust. Soc. Sugar Cane Technol. 25, 157-163.

Gomez, K.A. and Gomez, A.A. (1984). Statistical Procedures for Agricultural Research $\left(2^{\text {nd }}\right.$ ed.). John Wiley and Sons, NewYork.

Khan, I.A., Dahot, M.U., Seema, N., Yasmeen, S., Bibi, S., Raza, G., Khatri, A. and Naqvi, M.H. (2009). Direct regeneration of sugarcane plantlets: A tool to unravel genetic heterogeneity. Pak. J. Bot. 41(2), 797-814.

Lakshmanan, P., Geiskes, R. J., Wang, L., Elliott, A., Grof, C., P.L., Berding, N. and Smith. G.R. (2006). Development and hormone regulation of direct shoot organogenesis and somatic embryogenesis in sugarcane (Saccharum spp. Interspecific hybrids) leaf culture. Plant Cell Rep. 25,1007 - 1015.

Murashige, T. and Skoog, F. (1962). A revised medium for rapid Growth and Bio Assay with Tobacco Tissue Culture. Physiol. Plant. 15. [Online]. Available athttp://onlinelibrary.wiley.com/doi/10.1111/j.1399-3054.1962.tb08052.x/abstract.

[Accessed on 01.07.2017].

Perera, A.M.M.S. (2012). Assessment of sugarcane meristem culture procedure for virus elimination using serological techniques. M.Sc. thesis submitted to the Department of Plant Sciences, University of Colombo, Sri Lanka.

Perera, L., Meegahakumbura, M.K., Wijesekara, H.T.R., Fernando, W.B.S. and Dickinson, M.J. (2012). Aphytoplasma is associated with the Weligama Coconut Leaf Wilt Disease in Sri Lanka. J. Plant Pathol. 94(1), 205- 209.

Sesli, M. and Yegenoglu, E.D. (2010). Comparison of similarity coefficients used for cluster analysis based on RAPD markers in wild olives. Genet. Mol. Res. 9(4), 2248-2253.

Siegel, S. and Castellan, N.J. (1988). Nonparametric Statistics for Behavioral Sciences, McGraw Hill, New York.

Singh, R. (2007). Tissue culture studies of sugarcane. Department of Biotechnology and Environmental Sciences. Thapar Institute of Engineering and Technology Patiala -147004, India. 